\title{
Климонтов В. В.
}

«Научно-исследовательский институт клинической и экспериментальной мимфологии» - филиал ФГБНУ «ФеАеральный исследовательский центр Институт цитологии и генетики» СО РАН, Новосибирск, Россия

\section{ВАИЯНИЕ ВАРИАБЕАЬНОСТИ ГАИКЕМИИ НА РИСК РАЗВИТИЯ СЕРАЕЧНО-СОСУАИСТЫХ ОС ОЖНЕНИЙ ПРИ САХАРНОМ АИАБЕТЕ}

КАючевые слова: сахарный диабет; вариабельность гликемии; риск развития сердечно-сосудистых осложнений; атероскмероз.

Ссылка дяя цитирования: Климонтов В.В. Влияние вариабельности гликемии на риск развития

сердечно-сосудистых осложнений при сахарном диабете. Кардиология. 2018;58(10):80-87.

Резюме

Все большее количество Аанных свидетельствует о том, что повышенная вариабельность уровня глюкозы в крови (ВГ) является самостоятельным фактором риска развития сердечно-сосудистых осложнений при сахарном Аиабете (СА). Высокая ВГ у больных СА ассоциирована с выраженностью атеросклероза коронарных и сонных артерий. Влияние супрафизиологических колебаний гликемии на сосудистую стенку реализуется через процессы неферментативного гликирования, окислительный стресс, активацию воспацитемьных сигнацьных путей, Аисфункцию эндотелия; при этом эффекты высокой ВГ усугубцяют влияние хронической гипергликемии. В исслеАовании FinnDiane установлена связь вариабельности уровня гликированного гемоглобина $\left(\mathrm{HbA}_{1 \mathrm{c}}\right)$ с серАечно-сосудистыми осложнениями (инфаркт миокарда, вмешательство на коронарных сосудах, инсульт, ампутация конечности вследствие ишемии, операция на периферических сосуаах) у больных СА 1-го типа. В исследовании ADVANCE вариабельность уровня НbА натощак была ассоциирована с макрососудистыми осложнениями у больных СА 2-го типа; кроме того, вариабельность уровня $\mathrm{HbA}_{1 \mathrm{c}}$ была связана со смертностью от всех причин. В исследовании Verona Diabetes Study ВГ натощак являлась преАиктором смерти от сердечно-сосудистых причин у пожилых больных СА 2-го типа. Чрезмерные колебания гликемии во время госпитализации у больных с острым инфарктом миокараа и у больных СА во время чрескожных вмешательств на коронарных сосуАах повышают риск развития кардиальных осложнений. Эпизоды гипогликемии у больных СА с высокой ВГ могут способствовать увеличению риска развития аритмий, ишемии и инфаркта миокарАа, инсульта. ПреАставленные Аанные позволяют рассматривать ВГ как новую терапевтическую цель у больных СА с сердечно-сосуАистыми заболеваниями.

\section{Klimontov V.V.}

Research Institute of Clinical and Experimental Lymphology - Branch of the Institute of Cytology and Genetics, Novosibirsk, Russia

\section{IMPACT OF GLYCEMIC VARIABILITY on Cardiovascular Risk in Diabetes}

Keywords: diabetes mellitus; glucose variability; cardiovascular risk; atherosclerosis.

For citation: Klimontov V. V. Impact of Glycemic Variability on Cardiovascular Risk in Diabetes. Kardiologiia. 2018;58(10):80-87.

SumMARY

A growing body of evidences indicates the role of increased glucose variability (GV) as an independent cardiovascular risk factor in diabetes. It has been shown that high GV is associated with coronary and carotid atherosclerosis in diabetic subjects. The impact of enhanced glycemic fluctuations on vascular wall is mediated through non-enzymatic glycation, oxidative stress, activation of inflammatory pathways, and endothelial dysfunction. Thus, the effects of high GV exacerbate the influence of chronic hyperglycemia. The FinnDiane study established existence of a relationship between glycated hemoglobin $\left(\mathrm{HbA}_{1 \mathrm{c}}\right)$ variability and cardiovascular events (myocardial infarction, coronary artery procedure including by-pass surgery or angioplasty, stroke, limb amputation because of ischemia, or a peripheral artery procedure) in patients with type 1 diabetes. In ADVANCE study visit-to-visit HbA and fasting glucose variability was associated with cardiovascular events in type 2 diabetic subjects; moreover, $\mathrm{HbA}_{1 \mathrm{c}} \mathrm{variability}$ was associated with all-cause mortality. In Verona Diabetes Study, fasting GV was predictor of cardiovascular mortality in elderly patients with type 2 diabetes. In-hospital glycemic excursions in patients with acute myocardial infarction and in diabetic patients undergoing percutaneous coronary intervention predict the risk of adverse cardiac events. The episodes of hypoglycemia in diabetic patients with high GV may contribute to an increased risk of arrhythmias, myocardial ischemia and infarction, and stroke. The data presented give support to notion that GV could be considered a new therapeutic target in patients with diabetes and cardiovascular disease. 
T Тачиная с 80-х гг. прошлого века, основным критерием эффективности мечения больных сахарным Аиабетом (СА) является уровень гликированного гемоглобина $\left(\mathrm{HbA}_{1 \mathrm{c}}\right)$, содержание которого Аает преАставление о среднем (интегральном) уровне глюкозы в крови за последние 2-3 мес, но не позволяет суАить об амплитуде и частоте его колебаний. В послеАние годы накапливается все больше Аанных о том, что развитие осложнений СА опреАеляется не только среАним уровнем глюкозы, но и степенью изменчивости ее концентрации, т. е. вариабельностью гликемии (ВГ). В Аанном обзоре обобщены результаты исследований, посвященных влиянию ВГ на риск развития серАечно-сосудистых осложнений (ССО) у больных СА. Поиск источников осуществлен по базам данных Pubmed/Medline, Web of Science, ClinicalTrial. gov, E-library.

\section{Феномен ВГ в норме и при СА}

В структуре ВГ у зАорового человека можно выдемить несколько типов колебаний, повторяющихся в той или иной степени. Суточные колебания уровня глюкозы включают постпрандиальные колебания, связанные с поступлением глюкозы в кровь из желудочно-кишечного тракта после еАы и послеАующей утилизацией глюкозы в тканях под влиянием инсулина; колебания, связанные с физической нагрузкой, суточным ритмом секреции гормонов и чувствительности к инсулину. Межсуточные изменения гликемии менее заметны. Они могут возникать поА Аействием цикличных эндогенных факторов (например, фазных изменений секреции половых гормонов во время менструального цикла у женщин), формироваться в результате Аолгосрочных изменений характера питания и активности человека, поА Аействием стресса и т.А.

Почти $80 \%$ значений концентрации глюкозы, измеренных с помощью непрерывного мониторинга уровня глюкозы (НМГ), межат в Аиапазоне 3,3-5,5 ммомь/ около $20 \%$ - в Аиапазоне 5,6-7,8 ммоль / , более высокие значения составляют окомо $1 \%[1,2]$.

Нарушение секреции или действия инсулина привоАит не только к возрастанию среАнего уровня глюкозы в крови, но и к увеличению периода и амплитуды постпрандиальных колебаний гликемии. Увеличение ВГ возникает уже на Аоклинических этапах развития СА 1-го и 2-го типа. С началом сахароснижающей терапии появмяется риск выхода кривой гликемии в гипогликемический Аиапазон. Сложные гормонально-метаболические нарушения и осложнения, формирующиеся по мере развития СА, оказывают дополнительные, подчас разнонаправленные влияния на Аинамику гликемии. Наконец, большое влияние на ВГ оказывают характер питания и физической активности пациента, а также степень его вовлеченности в управление своим заболеванием.
Различают следующие основные факторы, влияющие на ВГ у больных СА [3]:

1. Гормонамьные нарушения: нарушения продукции инсулина; инсулинорезистентность; снижение секреции амилина; нарушения секреции инкретинов; нарушения секреции глюкагона.

2. Осложнения СА: автономная невропатия; гастропарез, нарушения всасывания; хроническая болезнь почек.

3. Аечение СА: сахароснижающие препараты; обучение больных; технические средства (инсулиновые помпы, $\mathrm{HM \Gamma )}$.

4. Поведение пациента: состав пищи; регулярность питания; физическая активность; самоконтроль гликемии; аАаптация питания и сахароснижающей терапии.

\section{Методы оценки ВГ}

Исходными Аанными Аля анализа ВГ у конкретного пациента с СА могут явмяться результаты повторных измерений уровня глюкозы в мабораторных условиях; Аанные, находящиеся в памяти инАивидуального глюкометра; Аанные, полученные с помощью НМГ.

Первые показатели ВГ были основаны на результатах измерения уровня глюкозы в мабораторных условиях, в том числе путем мониторинга концентрации глюкозы непосредственно в крови. Получаемые таким образом Аанные наиболее точны и позволяют изучать физиологические процессы, связанные с колебаниями гликемии. В клинической практике более полезным оказывается анализ ВГ по Аанным самостоятельного контромя гмикемии пациентом в повсеАневной жизни. При условии Алительного и регулярного использования инАивиАуального глюкометра в памяти прибора накапливается большой массив Аанных, ценность которого зависит от частоты, регулярности и Алительности контроля гликемии. Хотя эти Аанные Аискретные, заведомо неполные и значительно менее точные, чем мабораторные, они помогают выявить основные тренды колебаний гликемии у конкретного пациента. Наиболее Аетальная информация о колебаниях уровня глюкозы в интерстициальной жиАкости может быть получена с помощью НМГ.

Визуальный анализ ВГ включает оценку наличия, частоты и выраженности эпизодов гипо- и гипергликемии, оценку ампиитуды колебаний уровня глюкозы, выявление суточных и межсуточных тренАов гмикемической кривой. Аля количественного анализа предложено несколько Аесятков математических индексов, характеризующих размичные аспекты ВГ $[3,4]$. В ряА программ Аля анализа Аанных инАивиАуальных глюкометров и НМГ заложен расчет стандартного откАонения, индексов риска развития гипои гипергликемии и ряда Аругих параметров. Аля исслеАовательских задач применяется расчет индексов ВГ с помощью внешних программ. В качестве примера можно 
привести калькумятор EasyGV, разработанный исследовательской группой ОксфорАского университета [5].

Аля оценки Аолгосрочных трендов гликемии используют повторные измерения концентрации $\mathrm{Hb}_{1 \mathrm{c}}$ и $\mathrm{Apy-}$ гих гликированных протеинов (фруктозамина, альбумина). Своеобразной мерой постпрандиальных колебаний уровня глюкозы является 1,5-ангиАроглюцитол (1,5-АГ) метаболически нейтральный моносахариА, которых содержится в крови в высокой концентрации и свободно проходит через почечный фимьтр. В процессе реабсорбции в почечных канальцах 1,5-АГ конкурирует с глюкозой. Если колебания уровня глюкозы не превышают почечный порог, в моче обнаруживаются минимальные количества 1,5-АГ. В условиях гипергликемии, при выдемении больших количеств глюкозы реабсорбция 1,5-АГ блокируется, его экскреция увеличивается, а уровень в крови снижается. Концентрация 1,5-АГ в крови у больных СА коррелирует с постпрандиальной гипергликемией в послеАние 3-14 Аней [6].

\section{Патофизиомогия вАияния ВГ на сосуаистУю стенкУ}

\section{ГАюкозотоксичность и процессы гликирования}

В настоящее время вмияние ВГ на биохимические аномалии, индуцируемые гипергликемией, изучено Аишь частично. В условиях in vitro показано, что череАование нормального и высокого уровня глюкозы оказывает более выраженный активирующий эффект на протеинкиназу С в эндотелии, чем эффект стабильно высокого уровня глюкозы [7]. Патогенетическая роль протеинкиназы С в развитии сосуАистых осложнений СА связана со стимумяцией синтеза ряда митоген-активируемых киназ, транскрипционных факторов, факторов роста. С активацией протеинкиназы С связывают увеличение проницаемости сосудистой стенки, гиперпродукцию компонентов внеклеточного матрикса, нарушение внутриорганной гемодинамики. ПоврежАающее действие подъемов гликемии на сосуАистую стенку может реализоваться через неферментативное гликирование белков. Накопление конечных продуктов гликирования (КПГ) на Аолгоживущих белках нарушает обмен внеклеточного матрикса в сосудистой стенке. Кроме того, КПГ считают ответственными за усиление генерации свободных радикалов и активацию воспалительных сигнальных путей $[8]$.

\section{Окислительный стресс}

Исследования in vitro показали, что осцимляции уровня глюкозы инАуцируют окислительный и нитрозаминовый стресс в эндотелиальных клетках. При этом активируются ферменты, вовмеченные в процессы свободнорадикального повреждения и реализацию глюко- зотоксичности: протеинкиназа С, НААФН-оксиАаза, поли(ААФ)полимераза [9]. Чередование нормальной и высокой концентрации глюкозы явмяется более мощным индуктором свободнорадикальных окислительных процессов в эндотелиоцитах, чем стабильно повышенный уровень глюкозы $[7,10-12]$. Интермиттирующая гипергликемия у больных СА сопряжена с большей выраженностью окислительного стресса, чем постоянная гипергликемия [13].

АоПолнительным инАуктором процессов свободнорадикального окисления могут быть эпизоды гипогликемии. Показано, что Авухчасовая гипогликемия, индуцированная у больных СА 1-го типа, сопровожАается повышением уровня маркеров окислительного стресса: нитротирозина и 8-изо-простагландина-F $2 \alpha$ в плазме крови [14]. Аинамика показатемей посме гипогликемии зависела от того, возвращались ми значения гликемии в норму или переходили в диапазон гипергликемии. При восстановлении нормального уровня глюкозы у больных СА 1-го типа и зАоровых миц выраженность окислительного стресса уменьшалась, при индукции гипергликемии свободнорадикальные процессы еще более усиливались [15].

\section{Хроническое воспаление}

Активация воспалительных сигнальных путей играет важную роль в развитии сосудистых осложнений СА. У больных СА выявлена связь межАу концентрацией воспалительных маркеров и выраженностью коронарного атеросклероза [16, 17], толщиной интимы-медии сонных артерий [18], параметрами контромя гликемии [19-21]. Интермиттирующее повышение уровня глюкозы вызывало более выраженное увеличение экспрессии интермейкина-6 (IL-6), молекул аАгезии ICAM-1, VCAM-1 и Е-селектина в культивируемых клетках эндотелия чемовека, чем стабильно высокий уровень глюкозы $[10,11]$. У полростков с СА 1-го типа выявлена положительная взаимосвязь межАу ВГ и концентрацией высокочувствительного С-реактивного белка (вч-СРБ) [20]. У больных СА 2-го типа показаны корреляции межАу уровнем вч-СРБ, средней амплитудой колебаний гликемии и вариабельностью уровня $\mathrm{HbA}_{1 \mathrm{c}}$ в течение 2 мет [22]. У больных СА 1-го типа наблюдалось повышение уровня sICAM-1 и IL-6 в крови после Авухчасового эпизода гипогликемии [14]. Гипергликемия, сменяющая гипогликемию, вызывала Аальнейшее повышение концентрации sICAM-1 и IL-6 [23].

Важная роль в активации воспалительных сигнальных путей в условиях гипергликемии и окислительного стресса принадмежит ядерному фактору каппа B (NF-кB). Повышение уровня глюкозы вызывает активацию NF-кB в эндотелиоцитах, которая сохраняется и после восстановления нормального уровня глюкозы. Причиной 
АОАгосрочной активации NF-кB оказались эпигенетические модификации (метилирование гистонового белка H3K4me1) в промоторе гена субъединицы p65 NF-кB, индуцированные эпизодом гипергликемии [24].

\section{Аисфункиия эндотелия}

Накапливаются Аанные о влиянии нефизиологических колебаний гликемии на функцию эндотелиоцитов сосудов. Резкие изменения уровня глюкозы (от 11 до 43 ммоль $/ \Lambda)$, индуцированные периодическим введением инсулина, вызывали существенное снижение эндотемийзависимой вазодикатации у крыс с экспериментальным СА. Вазодикатация была нарушена в значительно большей степени у животных, которым периодически вводили инсулин, по сравнению с животными, не получавшими мечения, несмотря на более низкую среднюю гликемию в группе инсулинотерапии [25]. У больных СА 1-го типа изменения уровня глюкозы в Аиапазоне 5-15 ммоль/^ (каждые 6 ч на протяжении суток) приводили к более выраженному нарушению эндотемийзависимой вазодилатации по сравнению с таковым при стабильной гипергликемии (10 и 15 ммоль/л) [23]. Показано, что уменьшение эндотелийзависимой вазоАилатации при СА сопряжено с активацией экспрессии белка $166^{\text {Shc }}$ - ключевого Арайвера митохондриального окислительного стресса. У больных СА 2-го типа с недостаточно эффективным контролем гликемии выявлены эпигенетические модификации (гипометилирование АНК и ацетилирование гистонового белка 3-го типа) в промоторе гена $\mathrm{p} 66^{\mathrm{Shc}}$. Эти модификации сохранялись и после оптимизации гликемического контроля наряду с активацией свободнорадикальных процессов и нарушением функции эндотелия [26].

Имеются Аанные, что повышенная ВГ активирует апоптоз эндотелиальных кметок. Аанный эффект проАемонстрирован на эндотелиоцитах человека, культивируемых в среде с концентрацией глюкозы 5 ммоль/А, 20 ммоль/А и в условиях многократной смены данных концентраций. Стабильно высокий уровень глюкозы индуцировал апоптоз эндотелиальных кметок, что сопровожАалось снижением экспрессии противоапоптотического белка Bcl-2 и повышением экспрессии регумятора апоптоза Вах. Интермиттирующая гипергликемия индуцировала апоптоз на фоне практически полного подавмения экспрессии Bcl-2 и гиперэкспрессии Вах [27]. О более выраженном вмиянии осцимляций уровня глюкозы на апоптоз эндотелиальных кметок, в сравнении с эффектом стабильно высокого уровня глюкозы, сообщали и Аругие авторы [12].

Таким образом, роль ВГ в патогенезе сосудистых осложнений СА реализуется через усиление процессов гликирования, свободнорадикального окисления, акти- вацию воспалительных сигнальных путей, развитие Аисфункции энАотелия. Эффекты высокой ВГ при этом усугубляют вмияние хронической гипергликемии.

\section{ВГ и атероскмеротические поражения} сосудов у больных СА

Количество сообщений о связи ВГ с выраженностью атеросклеротических поражений сосудов у пациентов с СА постоянно увекичивается. У больных СА 2-го типа с ишемической болезнью серАца (ИБС) среАняя амплитуда колебаний гликемии (индекс MAGE: Mean Amplitude of Glucose Excursions) наряду с возрастом, уровнем вч-СРБ и $\mathrm{HbA}_{1 с}$ была ассоциирована со степенью коронарного атероскцероза, установценной по Аанным коронарографии [28]. Показана связь ВГ с составом атероскмеротических бляшек. В исследовании с участием пациентов с острым коронарным синаромом (ОКС), подвергшихся баммонной ангиопластике со стентированием, повышение средней амплитуды колебаний гликемии (MAGE) Аостоверно коррелировало с процентом перекрытия коронарных артерий атеросклеротическими бляшками, повышенным содержанием мипидов и сниженным фиброзированием бляшек, по Аанным внутрисосудистого умьтразвукового исследования. При этом не обнаружено связи размера и состава бляшек с уровнем $\mathrm{HbA}_{1 \mathrm{c}}$ или среАней гликемией [29].

ВАияние ВГ на прогрессирование коронарного атеросклероза установлено в проспективном исследовании (средняя Алительность наблюдения $11 \mathrm{мес),} \mathrm{включавшем}$ 88 больных с ОКС, не получавших сахароснижающей терапии. Индекс MAGE, рассчитанный по Аанным НМГ, оказался независимым предиктором прогрессирования атероскиероза, определявшегося как уменьшение диаметра сосуда $\geq 10 \%$ в случае $\geq 50 \%$ стеноза, или $\geq 30 \%$ в случае $<50 \%$ стеноза, развитие нового стеноза с $\geq 30 \%$ уменьшением Аиаметра сегмента или полной оккмюзии сосуАа [30].

У больных СА 2-го типа установмена прямая связь показателей ВГ, рассчитанных по результатам НМГ, с толщиной интимы-медии сонных артерий $[17,31]$.

\section{ВГ и риск развития ССО при СА}

С преАставлениями о патогенетической роли высокой ВГ в развитии осложнений согласуются результаты клинических исследований, показавшие связь ВГ с развитием и прогрессированием ангиопатий.

Первым крупным исследованием, показавшим связь сердечно-сосудистой патологии с ВГ у больных СА, стало Verona Diabetes Study. В этом исследовании оценивалась связь ВГ в состоянии натощак и смертности по данным за 5 мет у 566 пожилых больных СА 2-го типа. Вариабельность (но не уровень) гликемии натощак оказалась ассоциированной со смертностью от сердечно- 
сосуаистых причин $(\mathrm{p}=0,007)$, независимо от Аругих факторов риска. Смертность у пациентов с наибольшими значениями вариабельности (верхняя треть Аиапазона) была в 2,4 раза выше, чем у больных с наименьшей вариабемьностью [32].

В исследовании FinnDiane установлена связь вариабельности уровня $\mathrm{HbA}_{1 \mathrm{c}}$ с макрососуАистыми осложнениями у больных СА 1-го типа. Прогрессирование сосудистых осложнений отслеживалось у 2107 пациентов. За время наблюдения (в среАнем 5,7 года) ССО (инфаркт миокарАа - ИМ, вмешатемьство на коронарных сосудах, инсульт, ампутация конечности вслеАствие ишемии, операция на периферических сосудах) развились у 8,6\% больных. Величина стандартного отклонения (SD) $\mathrm{HbA}_{1 \mathrm{c}}$ показала ассоциацию с ССО, сохранявшую статистическую значимость после учета среднего уровня $\mathrm{HbA}_{1 c}$ и традиционных факторов риска (отношение шансов - ОШ 1,98 при 95\% Аоверительном интерваце - АИ от 1,39 Ао 2,82) [33].

Роль ВГ как предиктора развития сосудистых осложнений у больных СА 2-го типа показана в многоцентровом проспективном исследовании ADVANCE. Анализировалась вариабельность уровня $\mathrm{HbA}_{1 \mathrm{c}}$ и гликемии натощак у 4399 больных СА 2-го типа, входивших в группу интенсивного мечения. Вариабельность показатемей гликемического контроля оценивалась по Аанным измерений на 3, 6, 12, 18 и 24-м месяцах исследования. Первичная комбинированная конечная точка включала микро- и макрососуаистые осложнения. Риск развития микрососуаистых осложнений оценивался по комбинированной конечной точке, включавшей ретинопатию (развитие пролиферативной ретинопатии, макулярного отека, слепоты ими мазерной коагумяции сетчатки) и нефропатию (появмение макроальбуминурии, начало заместительной почечной терапии ими смерть от поражения почек). Макрососудистые осложнения вкмючами смерть от сердечно-сосудистых причин, нефатальный ИМ и нефатальный инсульт. Исследование показало минейную связь межАу вариабельностью (SD) уровня $\mathrm{HbA}_{1 \mathrm{c}}$ и гликемии натощак с комбинацией микро- и макрососуАистых осложнений ( $p=0,01$ и $\mathrm{p}=0,001$ соответственно), макрососудистыми осложнениями $(\mathrm{p}=0,02$ и $\mathrm{p}=0,001)$ и смертностью от всех причин $(\mathrm{p}=0,001$ и $\mathrm{p}=0,005)$ [34].

Проспективное наблюдение за больными СА 2-го типа в Гонконге (Hong Kong Diabetes Registry) подтверАило вмияние вариабельности уровня $\mathrm{HbA}_{1 \mathrm{c}}$ на риск развития ССО у больных СА 2-го типа. За время наблюдения (меАиана 7,2 года) макрососудистые осложнения (ИБС, сердечная недостаточность, ишемический инсульт, макроангиопатия нижних конечностей) развились у $10 \%$ больных. Эти больные имели более высокий среАний уровень и вариабельность $\mathrm{HbA}_{1 \mathrm{c}}(\mathrm{p}<0,001)$. В многофакторном анализе величина $\mathrm{SD}$ уровня $\mathrm{HbA}_{1 \mathrm{c}}$ быма ассоции- рована с риском развития макрососудистых осложнений (ОШ 1,27 при 95\% АИ от 1,15 Ао 1,4; p<0,001) [35].

Высокая ВГ в острый периоА ИМ может явмяться неблагоприятным прогностическим признаком, свиАетельствующим о риске развития осложнений. У пациентов старше 60 мет с уровнем глюкозы $<16,7$ ммоль $/ \Lambda$ (включая миц без СА в анамнезе) величина MAGE, вычисменная по показателям НМГ в острый периоА ИМ, является преАиктором ССО в течение слеАующего гоАа. Риск развития ССО (смерть от серАечно-сосудистых причин, повторный ИМ, острая сердечная недостаточность) быи повышен более чем в 3 раза среди пациентов с MAGE $>3,94$ ммоль $/ \Lambda$ (ОШ 3,1 при 95\% АИ от 1,19 Ао 8,12; $\mathrm{p}=0,02)[36,37]$.

Накапливаются Аанные о клиническом значении ВГ у пациентов, повергнутых кардиохирургическим вмешательствам. У больных СА высокая ВГ во время чрескожного коронарного вмешательства (преимущественно эпизоды гипогликемии) ассоциирована с риском развития ИМ во время процеауры [38]. У больных СА, перенесших аортокоронарное шунтирование, повышение ВГ связано с увеличением риска осложненного течения послеоперационного периода [39] и увеличением Алительности пребывания больного в стационаре [40].

Имеются Аанные о связи ВГ с желудочковой эктопической активностью. В ходе трехкратного мониторирования электрокардиограммы (на визите включения, через 3 и 6 мес) из 80 больных СА 2-го типа с хронической серАечной неАостаточностью желудочковые аритмии высоких градаций выявлены у 42 (53\%). Выраженные колебания уровня глюкозы в крови (MAGE $>5$ ммоль $/ \Lambda$ ) увеличивали риск развития жекудочковых аритмий в 2,3 раза $(\mathrm{p}=0,04)[41]$.

Гипогликемия явмяется важнейшим аспектом ВГ, оказывающим влияние на риск развития ССО. Исследования с применением НМГ показали гораздо более высокую распространенность эпизодов гипогликемии у больных СА, получающих сахароснижающую терапию, чем это преАполагалось ранее $[42,43]$. Известно, что эпизоды гипогликемии у больных СА чаще развиваются в периоды повышенной ВГ [44]. Параметры ВГ явмяются прогностическими инАикаторами развития гипогликемии [45].

В настоящее время роль тяжелой гипогликемии как преАиктора ССО у больных СА считается доказанной. Результаты исследований ADVANCE, ACCORD показали, что эпизоды тяжелой гипогликемии были ассоциированы с риском развития тяжелых ССО и увеличением смертности больных СА 2-го типа [46-48]. В исследовании ORIGIN тяжекая ночная гипогликемия оказалась фактором риска смерти от сердечно-сосудистых и Аругих причин у пациентов с преАиабетом и СА 2-го типа [49]. Недавние Аанные свидетельствуют о том, что нетяже- 
мая ночная гипогликемия ассоциирована с повышенным риском развития брадикарАии, желудочковых и преАсерАных нарушений ритма серАца [50].

Высокая ВГ с эпизодами гипогликемии может вмиять на электрическую стабильность миокарАа, модулируя симпатические и парасимпатические влияния на ритм сердца $[51,52]$. У больных СА 1-го и 2-го типа гипогликемия, индуцированная инсулином, ассоциирована с пролонгацией интервала QТ [53]. При одновременном мониторинге уровня глюкозы и эмектрокардиограммы у больных СА 2-го типа с ИБС эпизоды ишемии миокарАа чаще всего регистрируются во время клинически явных и бессимптомных гипогликемий [54]. Острые гемодинамические и гематологические изменения во время гипогликемии могут повышать риск развития ишемии мозга и мозгового инсульта [55].

Обобщая результаты приведенных исследований, можно заключить, что высокая вариабельность гликемии явмяется фактором риска развития сердечно-сосудистых заболеваний атеросклеротической природы и вероятным преАиктором смерти от сердечно-сосуаистых причин у пациентов с СА. Можно преАполагать, что связь ВГ с сердечно-сосуАистой патологией носит причинно-слеАственный характер, с учетом Аанных о влиянии нефизиомогических комебаний гликемии на сосудистую стенку и миокарА (см. рисунок 1).

В настоящее время не вполне понятно, какой именно аспект ВГ (периоА, амплитуАа колебаний, скорость изменения уровня глюкозы, наличие эпизодов гипогликемии и т. А.) вносит наибольший вклаА в развитие осложнений. Крупные исследования показали прогностическую значимость «крупноволновой» ВГ (вариабельности уровня $\mathrm{HbA}_{1 \mathrm{c}}$ и Аискретных значений уровня гмюкозы, зафиксированных с большими временны́ми промежутками). Роль суточных колебаний уровня глюкозы как преАиктора осложнений менее очевиАна.

В настоящее время не доказано, может ми снижение ВГ затормозить развитие ИБС и ее осложнений у больных СА. Результаты последних крупномасштабных ранАомизированных клинических исследований свидетельствуют о том, что риск развития ССО у больных СА 2-го типа может быть снижен при применении сахароснижающих препаратов - ингибиторов реабсорбции глюкозы в почках: эмпаглифмозина и канаглифмозина [56, 57],

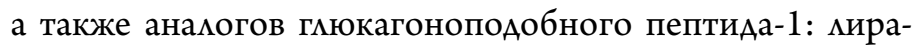
глутила и семаглутила $[58,59]$. Указанные препараты,



Рис. 1. ВАияние вариабельности гиикемии на риск развития серАечно-сосуАистых осложнений у бомьных сахарным Аиабетом.

ИБС - ишемическая болезнь серАца; ИМ - инфаркт миокарда.

наряАу с многочисленными плейотропными (негликемическими) эффектами на сердечно-сосудистую систему, уменьшают ВГ и практически не вызывают гипогликемии $[60,61]$.

\section{Закмючение}

Bсе большее количество Аанных свидетельствует о том, что повышенная вариабельность уровня глюкозы в крови является самостоятельным фактором риска развития сердечно-сосудистых осложнений при сахарном Аиабете. Влияние супрафизиологических колебаний гликемии на сосудистую стенку реализуется через процессы неферментативного гликирования, окислительный стресс, активацию воспалительных сигнальных путей и Аисфункцию энАотелия. В проспективных исслеАованиях установлена связь вариабельности уровня гликированного гемогмобина и гликемии натощак с сердечно-сосуАистыми осложнениями у больных СА 1-го и 2-го типа. Аанные о связи вариабельности гликемии с риском развития осложнений в очереАной раз подчеркивают важность Аеликатного контромя гликемии у больных сахарным Аиабетом с серАечно-сосуАистой патологией.

Автор декларирует отсутствие конфликта интересов, связанных с публикацией. 


\section{МИTEPATYPA/REFERENCES}

1. Freckmann G., Hagenlocher S., Baumstark A. et al. Continuous glucose profiles in healthy subjects under everyday life conditions and after different meals. J Diabetes Sci Technol 2007;1 (5):695-703.

2. Nomura K., Saitoh T., Kim G. U., Yamanouchi T. Glycemic profiles of healthy individuals with low fasting plasma glucose and HbAlc. ISRN Endocrinol 2011;2011:435047. DOI: $10.5402 / 2011 / 435047$.

3. Klimontov V.V., Myakina N.E. Glucose variability in diabetes. Novosibirsk: IPTZ NGU, 2016:252p. Russian (КАимонтов B. B., Мякина Н.Е. Вариабельность гликемии при сахарном диабете. Новосибирск: ИПЦ НГУ, 2016: 252c).

4. Klimontov V.V., Myakina N.E. Glycaemic variability in diabetes: a tool for assessing the quality of glycaemic control and the risk of complications. Diabetes Mellitus 2014;17 (2):18-24. Russian (КАимонтов В.В., Мякина Н.Е. Вариабельность гликемии при сахарном диабете: инструмент Аля оценки качества гликемического контроля и риска осложнений. Сахарный диабет 2014;17 (2):18-24.) DOI: 10.14341/DM20142.

5. Hill N. R., Nick S. O., Choudhary P. et al. Normal reference range for mean tissue glucose and glycemic variability derived from continuous glucose monitoring for subjects without diabetes in different ethnic groups. Diabetes Technol Ther 2011;13 (9):921-928.

6. Kim W.J., Park C.Y. 1,5-Anhydroglucitol in diabetes mellitus. Endocrine 2013;43 (1):33-40. DOI: 10.1007/s12020-012-9760-6.

7. Schisano B., Tripathi G., McGee K. et al. Glucose oscillations, more than constant high glucose, induce p 53 activation and a metabolic memory in human endothelial cells. Diabetologia 2011;54 (5):1219-1226. DOI: $10.1007 /$ s00125-011-2049-0.

8. Luo X., Wu J., Jing S., Yan L.J. Hyperglycemic Stress and Carbon Stress in Diabetic Glucotoxicity. Aging Dis 2016;7 (1):90-110. DOI: 10.14336/AD. 2015.0702.

9. Ihnat M.A., Thorpe J.E., Kamat C.D. et al. Reactive oxygen species mediate a cellular "memory" of high glucose stress signalling. Diabetologia 2007;50 (7):1523-1531.

10. Piconi L., Quagliaro L., Assaloni R. et al. Constant and intermittent high glucose enhances endothelial cell apoptosis through mitochondrial superoxide overproduction. Diabetes Metab Res Rev 2006;22 (3):198-203.

11. Quagliaro L., Piconi L., Assaloni R. et al. Intermittent high glucose enhances ICAM-1, VCAM-1 and E-selectin expression in human umbilical vein endothelial cells in culture: the distinct role of protein kinase $\mathrm{C}$ and mitochondrial superoxide production. Atherosclerosis 2005;183 (2):259-267.

12. Liu T. S., Pei Y.H., Peng Y.P. et al. Oscillating high glucose enhances oxidative stress and apoptosis in human coronary artery endothelial cells. J Endocrinol Invest 2014;37 (7):645-551. DOI: 10.1007/s40618-014-0086-5.

13. Ceriello A., Esposito K., Piconi L. et al. Oscillating glucose is more deleterious to endothelial function and oxidative stress than mean glucose in normal and type 2 diabetic patients. Diabetes 2008;57 (5):1349-1354. DOI: $10.2337 /$ db08-0063.

14. Ceriello A., Novials A., Ortega E. et al. Vitamin C further improves the protective effect of glucagon-like peptide-1 on acute hypogly cemia-induced oxidative stress, inflammation, and endothelial dysfunction in type 1 diabetes. Diabetes Care 2013;36 (12):4104 4108. DOI: $10.2337 / \mathrm{dc} 13-0750$.

15. Ceriello A., Novials A., Ortega E. et al. Hyperglycemia following recovery from hypoglycemia worsens endothelial damage and thrombosis activation in type 1 diabetes and in healthy controls. Nutr Metab Cardiovasc Dis 2014;24 (2):116-123. DOI: 10.1016/ j.numecd. 2013.05.003.

16. Su G., Mi S., Tao H. et al. Association of glycemic variability and the presence and severity of coronary artery disease in patients with type 2 diabetes. Cardiovasc Diabetol 2011;10:19. DOI: 10.1186/1475-2840-10-19.

17. Zhang X., Xu X., Jiao X. et al. The effects of glucose fluctuation on the severity of coronary artery disease in type 2 diabetes mellitus. J Diabetes Res 2013;2013:576916. DOI: 10.1155/2013/576916.
18. Alizadeh Dehnavi R., Beishuizen E.D., van de Ree M.A. et al. The impact of metabolic syndrome and CRP on vascular phenotype in type 2 diabetes mellitus. Eur J Intern Med 2008;19 (2):115-121. DOI: $10.1016 /$ j. ejim. 2007.06.011.

19. Vinagre I., Sánchez-Quesada J.L., Sánchez-Hernández J. et al. Inflammatory biomarkers in type 2 diabetic patients: effect of glycemic control and impact of LDL subfraction phenotype. Cardiovasc Diabetol 2014;13:34. DOI: 10.1186/1475-2840-13-34.

20. Hoffman R. P., Dye A. S., Huang H., Bauer J. A. Glycemic variability predicts inflammation in adolescents with type 1 diabetes. J Pediatr Endocrinol Metab 2016;29 (10):1129-1133. DOI: 10.1515/jpem2016-0139.

21. Klimontov V.V., Tyan N.V., Fazullina O.N. et al. Clinical and metabolic factors associated with chronic low-grade inflammation in type 2 diabetic patients. Diabetes mellitus 2016;19 (4):295302. Russian (КАимонтов В.В., Тян Н.В., Фазулмина О.Н. и Ар. Клинические и метаболические факторы, ассоциированные с хроническим воспалением низкой интенсивности, у больных сахарным диабетом 2-го типа. Сахарный Аиабет 2016;19 (4):295-301). DOI: $10.14341 / \mathrm{DM} 7928$.

22. Chang C. M., Hsieh C. J., Huang J. C., Huang I. C. Acute and chronic fluctuations in blood glucose levels can increase oxidative stress in type 2 diabetes mellitus. Acta Diabetol 2012;49 (Suppl. 1):S171S177. DOI: $10.1007 /$ s00592-012-0398-x.

23. Ceriello A., Novials A., Ortega E. et al. Glucagon-like peptide 1 reduces endothelial dysfunction, inflammation, and oxidative stress induced by both hyperglycemia and hypoglycemia in type 1 diabetes. Diabetes Care 2013;36 (8):2346-2350. DOI: 10.2337/dc12-2469.

24. El-Osta A., Brasacchio D., Yao D. et al. Transient high glucose causes persistent epigenetic changes and altered gene expression during subsequent normoglycemia. J Exp Med 2008;205 (10):2409-2417. DOI: $10.1084 /$ jem. 20081188.

25. Horvath E.M., Benko R., Kiss L. et al. Rapid glycaemic swings induce nitrosative stress, activate poly- (ADP-ribose) polymerase and impair endothelial function ina rat model of diabetes mellitus. Diabetologia 2009;52 (5):952-961. DOI: 10.1007/ s00125-009-1304-0.

26. Costantino S., Paneni F., Battista R. et al. Impact of Glycemic Variability on Chromatin Remodeling, Oxidative Stress and Endothelial Dysfunction in Type 2 Diabetic Patients with Target HbAlc Levels. Diabetes 2017. pii: db170294. DOI: $10.2337 / \mathrm{db} 17-0294$.

27. Risso A., Mercuri F., Quagliaro L. et al. Intermittent high glucose enhances apoptosis in human umbilical vein endothelial cells in culture. Am J Physiol Endocrinol Metab 2001;281 (5):E924 - E930.

28. Su G., Mi S., Tao H. et al. Association of glycemic variability and the presence and severity of coronary artery disease in patients with type 2 diabetes. Cardiovasc Diabetol 2011;10:19. DOI: 10.1186/1475-2840-10-19.

29. Okada K., Hibi K., Gohbara M. et al. Association between blood glucose variability and coronary plaque instability in patients with acute coronary syndromes. Cardiovasc Diabetol 2015;14:111. DOI: $10.1186 / \mathrm{s} 12933-015-0275-3$.

30. Kataoka S., Gohbara M., Iwahashi N. et al. Glycemic variability on continuous glucose monitoring system predicts rapid progression of non-culprit lesions in patients with acute coronary syndrome. Circ J 2015;79:2246-2254. DOI: 10.1253/ circj. CJ-15-0496.

31. Mo Y., Zhou J., Li M. et al. Glycemic variability is associated with subclinical atherosclerosis in Chinese type 2 diabetic patients. Cardiovasc Diabetol 2013;12:15. DOI: 10.1186/1475-2840-12-15.

32. Muggeo M., Zoppini G., Bonora E. et al. Fasting plasma glucose variability predicts 10-year survival of type 2 diabetic patients: the Verona Diabetes Study. Diabetes Care 2000;23 (1):45-50.

33. Wadén J., Forsblom C., Thorn L.M. et al.; Finnish Diabetic Nephropathy Study Group. A1C variability predicts incident cardiovascular events, microalbuminuria, and overt diabetic nephropathy in patients with type 1 diabetes. Diabetes 2009;58 (11):26492655. DOI: $10.2337 /$ db09-0693. 
34. Hirakawa Y., Arima H., Zoungas S. et al. Impact of visit-to-visit glycemic variability on the risks of macrovascular and microvascular events and all-cause mortality in type 2 diabetes: the ADVANCE trial. Diabetes Care 2014;37 (8):2359-2365. DOI: 10.2337/dc14-0199.

35. Luk A. O., Ma R.C., Lau E.S. et al. Risk association of HbA1c variability with chronic kidney disease and cardiovascular disease in type 2 diabetes: prospective analysis of the Hong Kong Diabetes Registry. Diabetes Metab Res Rev 2013;29 (5):384-390. DOI: 10.1002/dmrr. 2404.

36. Su G., Mi S. H., Li Z. et al. Prognostic value of early in-hospital glycemic excursion in elderly patients with acute myocardial infarction. Cardiovasc Diabetol 2013;12:33. DOI: 10.1186/1475-2840-12-33.

37. Su G., Mi S. H., Tao H. et al. Impact of admission glycemic variability, glucose, and glycosylated hemoglobin on major adverse cardiac events after acute myocardial infarction. Diabetes Care 2013;36 (4):1026-1032. DOI: $10.2337 / \mathrm{dc} 12-0925$.

38. Nusca A., Lauria Pantano A., Melfi R. et al. Glycemic Variability Assessed by Continuous Glucose Monitoring and Short-Term Outcome in Diabetic Patients Undergoing Percutaneous Coronary Intervention: An Observational Pilot Study. J Diabetes Res 2015;2015:250201. DOI: 10.1155/2015/250201.

39. Subramaniam B., Lerner A., Novack V. et al. Increased glycemic variability in patients with elevated preoperative $\mathrm{HbA1C}$ predicts adverse outcomes following coronary artery bypass grafting surgery. Anesth Analg 2014;118 (2):277-287. DOI: 10.1213/ANE. 0000000000000100.

40. Bansal B., Carvalho P., Mehta Y. et al. Prognostic significance of glycemic variability after cardiac surgery. J Diabetes Complications 2016;30 (4):613-617. DOI: 10.1016/j. jdiacomp. 2016.02.010.

41. Pochinka I.G., Strongin L.G., Struchkova Yu. V. Variability of Glycemia and Ventricular Rhythm Disturbances in Patients With Chronic Heart Failure and Type 2 Diabetes Mellitus. Kardiologiia 2013;53 (9):47-51. Russian (Починка И.Г., Стронгин М.Г., Стручкова Ю.В. Вариабельность гликемии и желудочковые нарушения ритма у больных хронической сердечной неАостаточностью, страдающих сахарным Аиабетом 2-го типа. КарАиология 2013;53 (9):47-51).

42. Klimontov V. V., Tsiberkin A. I., Fazullina O. N. et al. Hypoglycemia in type 2 diabetes patients treated with insulin: the advantages of continuous glucose monitoring. Diabetes Mellitus 2014;17 (1):75-80. Russian (КАимонтов В.В., Циберкин А.И., Фазумиина О.Н. и Ар. Гипогликемии у пожилых больных сахарным диабетом 2-го типа, получающих инсулин: результаты непрерывного мониторирования гмюкозы. Сахарный диабет 2014;17 (1):75-80.) DOI: 10.14341/DM2014175-80.

43. Pazos-Couselo M., García-LópezJ. M., González-Rodríguez M. et al. High incidence of hypoglycemia in stable insulin-treated type 2 diabetes mellitus: continuous glucose monitoring vs. self-monitored blood glucose. Observational prospective study. Can J Diabetes 2015;39 (5):428-433. DOI: 10.1016/j. jcjd. 2015.05.007.

44. Kovatchev B.P., Cox D.J., Farhy L.S. et al. Episodes of severe hypoglycemia in type 1 diabetes are preceded and followed within 48 hours by measurable disturbances in blood glucose. J Clin Endocrinol Metab 2000;85:4287-4292.

45. Klimontov V.V., Myakina N.E. Glucose variability indices predict the episodes of nocturnal hypoglycemia in elderly type 2 diabetic patients treated with insulin. Diabetes Metab Syndr 2017;11 (2):119-124. DOI: $10.1016 / j$. dsx. 2016.08.023

46. Zoungas S., Patel A., Chalmers J. et al.; ADVANCE Collaborative Group. Severe hypoglycemia and risks of vascular events and death. N Engl J Med 2010;363 (15):1410-1418. DOI: 10.1056/NEJMoa1003795.

47. Bonds D.E., Miller M.E., Bergenstal R.M. et al. The association between symptomatic, severe hypoglycaemia and mortality in type 2 diabetes: retrospective epidemiological analysis of the ACCORD study. BMJ 2010;340: b4909. DOI: 10.1136/bmj. b4909.

48. Duckworth W., Abraira C., Moritz T. et al.; VADT Investigators. Glucose control and vascular complications in veterans with type 2 diabetes. N Engl J Med 2009;360 (2):129-139. DOI: 10.1056/NEJMoa0808431.

49. ORIGIN Trial Investigators, Mellbin L. G., Rydén L., Riddle M.C. et al. Does hypoglycaemia increase the risk of cardiovascular events? A report from the ORIGIN trial. Eur Heart J 2013;34:3137-3144. DOI: 10.1093 /eurheartj/eht332.

50. Chow E., Bernjak A., Williams S. et al. Risk of cardiac arrhythmias during hypoglycemia in patients with type 2 diabetes and cardiovascular risk. Diabetes 2014;63:1738-1747. DOI: 10.2337/db13-0468.

51. Myakina N.E., Klimontov V. V., Safarov D. M. Glucose fluctuations and heart rate variability in type 2 diabetic patients: the results of simultaneous glucose and ECG monitoring. Diabetes 2015;64 (S. 1):A166.

52. Klimontov V.V., Myakina N.E., Tyan N.V. Heart rate variability is associated with interstitial glucose fluctuations in type 2 diabetic women treated with insulin. Springerplus 2016;5 (1):1-9. DOI: 10.1186/s40064-016-1932-z.

53. Lee A.S., Brooks B.A., Simmons L. et al. Hypoglycaemia and QT interval prolongation: Detection by simultaneous Holter and continuous glucose monitoring. Diabetes Res Clin Pract 2016;113:211-214. DOI: 10.1016/j. diabres. 2016.01.005.

54. Desouza C., Salazar H., Cheong B. et al. Association of hypoglycemia and cardiac ischemia: a study based on continuous monitoring. Diabetes Care 2003;26:1485-1489.

55. Wright R.J., Frier B.M. Vascular disease and diabetes: is hypoglycaemia an aggravating factor? Diabetes Metab Res Rev 2008;24 (5):353-363.

56. Zinman B., Wanner C., Lachin J. M. et al.; EMPA-REG OUTCOME Investigators. Empagliflozin, Cardiovascular Outcomes, and Mortality in Type 2 Diabetes. N Engl J Med 2015;373 (22):21172128. DOI: $10.1056 /$ NEJMoa 1504720.

57. Neal B., Perkovic V., Mahaffey K.W. et al.; CANVAS Program Collaborative Group. Canagliflozin and Cardiovascular and Renal Events in Type 2 Diabetes. N Engl J Med 2017;377 (7):644-657. DOI: 10.1056/NEJMoa1611925.

58. Marso S.P., Daniels G.H., Brown-Frandsen K. et al.; LEADER Steering Committee; LEADER Trial Investigators. Liraglutide and Cardiovascular Outcomes in Type 2 Diabetes. N Engl J Med 2016;375 (4):311-322. DOI: 10.1056/NEJMoa1603827.

59. Marso S. P., Bain S. C., Consoli A. et al.; SUSTAIN-6 Investigators. Semaglutide and Cardiovascular Outcomes in Patients with Type 2 Diabetes. N Engl J Med 2016;375 (19):1834-1844.

60. Dandona P. Minimizing glycemic fluctuations in patients with type 2 diabetes: approaches and importance. Diabetes Technol Ther 2017;19 (9). DOI: 10.1089/dia. 2016.0372.

61. Rodbard H. W., Peters A. L., Slee A. et al. The Effect of Canagliflozin, a Sodium Glucose Cotransporter 2 Inhibitor, on Glycemic End Points Assessed by Continuous Glucose Monitoring and PatientReported Outcomes Among People With Type 1 Diabetes. Diabetes Care 2017;40 (2):171-180. DOI: $10.2337 /$ dc16-1353.

Поступима 11.08.17 (Received 11.08.17) 